Estudios Constitucionales, Año 13, № 2, 2015, pp. 153-168

ISSN 07180195

Centro de Estudios Constitucionales de Chile Universidad de Talca

"SSon válidas las modificaciones al capítulo de reforma constitucional?

Una reflexión sobre la autorreferencia normativa de Alf Ross y sus detractores"

Miriam Lorena Henríquez Viñas - George Lambeth Vicent

\title{
¿SON VÁLIDAS LAS MODIFICACIONES AL CAPÍTULO DE REFORMA CONSTITUCIONAL? UNA REFLEXIÓN SOBRE LA AUTORREFERENCIA NORMATIVA DE ALF ROSS Y SUS DETRACTORES*
}

\author{
¿ARE VALID THE CHANGES TO CHAPTER OF CONSTITUTIONAL REFORM? \\ AN ANALYSIS OF SELF NORMATIVE REFERENCE \\ BY AlF Ross AND HIS OPPONENTS
}

\author{
Miriam Lorena Henríquez Viñas ${ }^{1}$ \\ Profesora Derecho Constitucional \\ Universidad Alberto Hurtado \\ mhenriqu@uahurtado.cl \\ George Lambeth Vicent ${ }^{2}$ \\ Profesor Derecho Comparado \\ Universidad Alberto Hurtado \\ george.lambeth@gmail.com
}

RESUMEN: En el actual momento constitucional chileno, el trabajo presenta la discusión en torno a la validez o invalidez de la modificación de las normas sobre reforma constitucional en virtud del procedimiento que estas últimas fijan. Para ello se explica la vía propuesta de cambio constitucional que implicaría una reforma previa a la Constitución vigente, luego se exponen los argumentos a favor y en contra de la validez de las normas que modifican las normas sobre la reforma constitucional y finalmente se expresa la relevancia jurídica de este debate en el contexto del cambio constitucional chileno.

ABSTRACT: In the current Chilean constitutional debate, this research presents the debate concerning the validity of the amendment of the constitutional amendment rule by its own process. In doing so, the article explain the way by witch the Chilean Constitution may be reform using the procedure recognize by it. Then, the article explores the arguments in favor and against the validity of the norm resulting from the amendment of the constitutional amendment norm by its own

* Trabajo recibido el 15 de julio de 2015 y aprobado el 21 de octubre de 2015.

1 Abogado, Universidad Nacional del Comahue (Argentina). Magíster en Derecho Público, Pontificia Universidad Católica de Chile (Chile). Doctor en Ciencias Jurídicas, Universidad de Santiago de Compostela (España). Profesora de Derecho Constitucional de la Universidad Alberto Hurtado.

2 Abogado, Universidad de Chile. Magíster (c) Universidad de Chile. Profesor de Derecho Comparado de la Universidad Alberto Hurtado. 
process. This analysis allows the authors to acknowledge the relevance of this debate in the Chilean constitutional reform context.

PALABRAS CLAVE: Cambio constitucional; reforma constitucional; normas sobre reforma constitucional; validez.

KEY WORDS: Constitutional change; constitutional reform; norms of constitutional reform; validity.

\section{INTRODUCCIÓN}

Todas las constituciones necesitan adecuaciones en el tiempo, en la medida en que el mundo y la comunidad política experimentan cambios ${ }^{3}$. Algunas de las razones que se exponen para justificar el cambio constitucional son: a) la sustitución de régimen político por otro; b) la necesidad de crear una identidad nacional a través de un proceso constituyente participativo; c) el surgimiento de nuevos movimientos sociales y coaliciones políticas; d) la modificación de las circunstancias económicas, culturales e internacionales, entre otras.

Sin perjuicio de las razones apuntadas, en el caso chileno se han invocado los siguientes motivos para promover un cambio constitucional profundo que concluya en la reforma total o el dictado de una nueva Constitución: a) la ilegitimidad de origen de la actual Constitución, al tratarse de una Carta impuesta en el contexto de un régimen autoritario cívico-militar ${ }^{4}$; b) la ilegitimidad democrática de su contenido, al consagrar lo que se ha denominado una democracia protegida del pueblo5; c) la persistencia de "enclaves autoritarios" o "cerrojos" en el articulado constitucional vigente ${ }^{6}$; d) la necesidad de que un país democrático se rija por

3 Ginsburg, Tom (2014), p. 16; BöCKenforde (2000), p. 181.

4 Francisco Zúñiga expresa sobre el particular: "La idea total subyacente a la nueva Constitución es superar la vieja Constitución, estatuto del poder otorgado, autoritario en lo político y neoliberal en lo económico, con nula legitimidad democrática de origen, al estar fundada en un "fraude" plebiscitario y adicionalmente estar aquejada de una muy parcial e insatisfactoria legitimidad de ejercicio". ZúNiga, Francisco (2014), p. 309.

5 Fernando Atria, en su libro La Constitución tramposa afirma que la actual Carta es una Constitución al derecho pero no al revés, que es una norma fundante, pero no una decisión fundamental del pueblo sobre su identidad y forma de existencia. Esto porque sus normas no le dan forma política al pueblo chileno con la finalidad propiamente constitucional de habilitarlo para actuar, sino con la finalidad precisa de neutralizar su agencia, de impedir que actúe. Por tanto, a juicio de Atria, la decisión fundamental de la Constitución de 1980 es negar al pueblo potestad para actuar. Pero, señala el autor, si es una decisión cuyo contenido fundamental es negar la agencia política del pueblo, entonces no puede ser una decisión del pueblo sobre su forma política, sino una que se lo impone. Por eso "es correcto decir que la llamada Constitución de 1980 es esencialmente antidemocrática o, lo que es lo mismo, que no es una constitución”. ATRiA, Fernando (2013), p. 45.

6 Fernando Atria, quien se refiere a los cerrojos de la Constitución, expone que las reformas previas a la Constitución tuvieron como objeto eliminar los cerrojos que ya estaban gastados pero que no tocaron los 
una Carta democrática ${ }^{7}$; e) lo imperioso de contar con una Constitución basada en un pacto, acuerdo o contrato nacional que refleje el pluralismo político y la diversidad social actual ${ }^{8}$; y f) las deficiencias técnicas de un texto reformado en múltiples ocasiones 9 .

Por su parte, las vías que se han propuesto a nivel nacional para satisfacer este "momento constitucional"10 se diferencian por sus grados de intensidad y van desde: a) reformas parciales a la Carta vigente; b) reformas parciales a la Carta actual seguida de una reforma total; y c) la generación de una nueva Constitución sin necesidad de reformar la actualmente vigente, a través de un congreso constituyente, asamblea constituyente o referéndum constituyente.

Las interrogantes que plantea la segunda alternativa -reformas parciales intermedias para la reforma total o el dictado de una nueva Constitución- son múltiples, entre las cuales podemos mencionar: a) ¿Es mejor hacer cambios específicos progresivos, a través de enmiendas constitucionales, que una revisión

cerrojos que están vivos, los que continúan neutralizando la agencia política del pueblo. Si el problema es "gatopardismo", la solución que propone Atria es "antigatopardismo", es decir, poco tiene que cambiar para que todo sea distinto. En sus palabras: "Es necesario eliminar todos los cerrojos para tener una nueva Constitución”. Tales cerrojos son, a su juicio, las leyes orgánicas constitucionales y sus quórum de aprobación, el sistema binominal, el control preventivo del Tribunal Constitucional y el metacerrojo de los quórums reforzados de reforma constitucional. ATRIA (2013), pp. 46-55.

7 Así lo expresa Lautaro Ríos, quien con vehemencia expresa: "No es el justificado repudio a la Constitución de 1980, ni a la forma en que ella fue elaborada, ni a la manera en que se nos impuso, ni a los contenidos autoritarios que subsisten en ella, lo que justifica el anhelo de elaborar una nueva Constitución. Es la necesidad que nace desde lo más profundo de nuestras raíces democráticas lo que nos impulsa a hacer realidad este sueño insatisfecho". Ríos, Lautaro (2013), p. 212.

8 Francisco Zúñiga concluye en un reciente artículo que la nueva Constitución debe ser el fruto del poder constituyente derivado o del poder constituyente originario, soportada sobre un gran acuerdo nacional acerca de sus "bases", acuerdo que debe reflejar en la mayor medida de lo posible el pluralismo político e ideológico de la sociedad. ZúNíiga (2014), p. 317.

9 Pablo Ruiz Tagle expresa su preocupación por el centenar de modificaciones introducidas a la Carta Constitucional, pues a pesar de estos cambios la Constitución sigue siendo no democrática, ni republicana y con graves problemas técnicos. En sus palabras: "Díganme ustedes si no se han sentido tan incómodos y desubicados ante la Constitución vigente, como ese perro perdido y desubicado en la iglesia que describe en su imagen Lampedusa. Y es por esa incomodidad que tenemos en Chile, lo que se deriva del efecto constitucional 'gatopardo', que la democracia solo puede consolidarse con una mutación constitucional que supere el proyecto 'pinochetista' y asiente un liderazgo pro democrático en el Congreso y en el Tribunal Constitucional”. Ruiz Tagle, Pablo (2012), p. 135.

10 Como es sabido, Ackerman establece un tipo de criterio formal que determinará si nos encontramos ante un momento constitucional o no, con independencia del estado de convulsión de la ciudadanía. ACKERMAN, Bruce (1989), pp. 453-547. 
total?; b) ¿Con cuáles mayorías procede reformar la Constitución para establecer un proceso que dé origen a una reforma total de la Constitución?; c) ¿Las normas sobre la reforma solo se encuentran previstas en el capítulo XV de la Constitución?; d) ¿Cuál es el rol del Tribunal Constitucional en el control de constitucionalidad de la reforma constitucional? y ¿cuál es el alcance del control?; e) ¿El poder constituyente derivado o reformador está sujeto a límites materiales?; f) ¿'Son enmienda y reemplazo simples sustituciones o existe una forma de identidad en el período de vigencia de una Constitución que no puede ser alterado?; g) ¿Es válida la revisión total de la Constitución o solo son válidas las reformas parciales?; h) ¿Es válido modificar las normas sobre la reforma constitucional en virtud del procedimiento que estas últimas fijan? Como adelantamos, sin perjuicio del interés que suscitan todos estos asuntos, el presente trabajo solo versará sobre la última interrogante.

De esta forma, la hipótesis que planteamos se traduce en la pregunta: ¿Son válidas las normas que modifican, en el sentido de agregar, eliminar o sustituir, las normas sobre la reforma constitucional en base al procedimiento que estas últimas fijan?

Este asunto no ha sido analizado mayormente por la dogmática constitucional chilena, sino que se ha desarrollado en el contexto del debate más amplio de la teoría del derecho, redundando incluso en la validez de los sistemas jurídicos. Sin perjuicio de la amplitud del ámbito de discusión, el objetivo de este artículo es preciso: dar cuenta del referido debate y de esta manera aportar un nuevo insumo a la discusión en el actual momento constitucional.

Para la consecución de lo anterior, proponemos el siguiente plan de análisis. En primer término, identificaremos el mecanismo de cambio constitucional propuesto en el mes de octubre por la Presidenta Michelle Bachelet que implica una reforma constitucional previa a las normas sobre reforma constitucional. Luego, explicitaremos los argumentos esgrimidos en contra y a favor de la validez de las normas que modifican las normas sobre la reforma constitucional mediante el mecanismo que ellas mismas disponen. En tercer término, y a modo de conclusión, plantearemos la relevancia jurídica del debate en el actual momento constitucional que experimenta Chile.

\section{LA REFORMA PREVIA DE LAS NORMAS DE REFORMA CONSTITUCIONAL}

El Programa de Gobierno de la Presidenta Michelle Bachelet tiene como uno de sus ejes centrales iniciar un proceso constituyente que permita a los chilenos darse una nueva Constitución en democracia. 
A la fecha de este trabajo el procedimiento para tal fin se encuentra definido y se desarrollará conforme a las siguientes etapas: a) una primera fase (noviembre de 2015 a marzo de 2016) de educación cívica-constitucional; b) una segunda fase (marzo a octubre de 2016) de diálogos ciudadanos a nivel comunal, provincial y regional que culminará en la elaboración de una síntesis a nivel nacional. El resultado de estos diálogos serán las bases ciudadanas para la nueva Constitución que permitirá elaborar un proyecto de nueva Constitución. Todo ello acompañado de un consejo ciudadano de observadores; c) A fines de 2016 se enviará al Congreso Nacional un proyecto de reforma constitucional con el objetivo de agregar una normativa en la que se establezcan los procedimientos para dictar una nueva Constitución. Tal reforma constitucional se aprobará con el voto de las dos terceras partes de los senadores y diputados en ejercicio. La propuesta de reforma constitucional supondrá que la nueva Constitución se origine en alguno de los siguientes procedimientos que defina el Congreso Nacional elegido en 2017 por las tres quintas partes de los senadores y diputados en ejercicio: comisión bicameral de senadores y diputados, convención constituyente mixta, asamblea constituyente o un plebiscito convocado por el Congreso para que sea la ciudadanía la que decida, entre las tres alternativas anteriores, la forma en que se deliberará y aprobará la nueva Constitución; d) A inicios del segundo semestre de 2017 se presentará el proyecto de nueva Constitución originada en las bases ciudadanas, a fin de que sea discutido por la instancia constituyente que el Congreso Nacional defina; e) Finalmente el proyecto sancionado por la instancia constituyente que corresponda será sometido a un plebiscito ratificatorio vinculante por parte de la ciudadanía.

Como se observa, una de las etapas del proceso constituyente definido importa una modificación a las normas sobre la reforma constitucional en el sentido de permitir la sustitución de la actual Constitución o su reforma total.

Previo a iniciar el análisis sobre la validez de esta futura modificación constitucional, corresponde distinguir entre las normas sobre producción de la reforma, en adelante normas sobre la reforma o NSR, y las reformas concretas, en adelante, normas de reforma o NR. Las primeras dicen relación con la producción y las segundas corresponden a las normas concretas realizadas conforme a las anteriores ${ }^{11}$. Las normas sobre la reforma son normas de competencia, por cuanto fijan el ámbito posible de la reforma y el procedimiento

11 De Cabo, Carlos (2003), p. 29. En un sentido coincidente, Henríquez, Miriam (2011), p. 463. 
para reformar la Constitución ${ }^{12}$. La principal consecuencia de esta afirmación es que la norma de reforma que sea promulgada, por ejemplo, por un órgano distinto o por un procedimiento diferente de aquel fijado por la norma sobre la reforma, será inválida o inconstitucional ${ }^{13}$.

\section{LA DISCUSIÓN SOBRE LA VALIDEZ DE LAS NORMAS QUE MODIFICAN LAS NORMAS SOBRE LA REFORMA CONSTITUCIONAL}

\section{A. El debate de los teóricos del derecho}

A nivel comparado, desde la década del 50 en adelante del siglo XX, la discusión sobre la (in)validez de las normas que modifican las normas sobre la reforma se originó en las publicaciones de una serie de trabajos del filósofo del derecho danés, Alf Ross. A las propuestas de Ross le siguieron una serie de respuestas críticas de varios de los más destacados teóricos del derecho, tales como Finnis, Hart, Hoerster, Nino y Raz ${ }^{14}$.

Recapitulando, las razones que han esgrimido para negar la validez de las normas que modifican las normas sobre la reforma constitucional conforme a las reglas fijadas por las primeras son a) si las normas sobre la reforma se aplican a ellas mismas serían autorreferentes, careciendo de sentido los enunciados autorreferentes y b) una disposición de reforma constitucional no puede ser reformada válidamente por el procedimiento por ella misma establecido, porque ello supone delegar la competencia de reforma constitucional, vulnerando así la reserva de constitución establecida por la propia norma de reforma constitucional.

La primera tesis es sostenida por Alf Ross, quien señala que si el artículo de reforma constitucional -artículo 88 de la Constitución danesa- se aplicara a sí mismo sería autorreferente y ello se opone a lo que él mismo denomina un "teorema lógico según el cual los enunciados autorreferentes carecen de sentido" 15 .

12 Moreso afirma que estas disposiciones han sido, en varias ocasiones, calificadas de normas de competencia por autores como Guastini, Nino y Ross. Moreso, José Juan (1991), p. 202.

13 Henríquez (2011), p. 464.

14 Solo por nombrar algunas de las respuestas más conocidas: Finnis (1973); HarT (1964); HoERSTER (1972); NinO (1985); RAZ (1972), entre otras respuestas o incursiones en el debate.

15 Alf Ross cita un trabajo del filósofo danés Jörgen Jörgensen para quien ningún enunciado se refiere a sí mismo o que no hay enunciados autorreferentes. La cuestión central en el argumento que sostiene Jörgensen puede resumirse en cuatro tesis:

(i) No hay relaciones autorreferentes o cualquier otro fenómeno de los así llamados autorreflexivos.

(ii) En especial, ningún lenguaje o expresión lingüística con sentido es (o puede ser) autorreferente. 
Luego, la reforma del artículo que establece el mecanismo de reforma utilizando ese mismo mecanismo, conduce a una contradicción.

Alf Ross muestra la contradicción a la que se llegaría si se aceptaran los supuestos mencionados, basados en las relaciones entre normas estatuidas por normas de competencia y las normas de competencias también ellas como normas estatuidas. El punto de Ross es explicitar el regreso al infinito salvo que se decida que, respecto de una norma de competencia, no se puede predicar que fuera aprobada por ninguna otra autoridad ${ }^{16}$.

Véase el siguiente esquema propuesto por Ross:

A1 está constituido por $\mathrm{C} 1$; $\mathrm{C} 1$ es promulgada por $\mathrm{A} 2$;

A2 está constituido por C2; C2 es promulgada por A3, y

A3 está constituido por C3; C3 no es aprobada por ninguna otra autoridad.

Donde An es cualquier autoridad dotada de potestad normativa que puede o no (contingente) haber sido constituida por $\mathrm{Cn}$. Y donde $\mathrm{Cn}$ es el conjunto de todas las reglas que configuran esa potestad.

En consecuencia, A3 es la máxima autoridad del sistema y C3 su norma básica. ¿Pero qué sucede con C3? ¿Cómo se pudo establecer la existencia legal de C3? Para Ross hay solamente dos respuestas posibles. Pero ambas son inaceptables, quedando en evidencia el denominado puzle constitucional de Ross.

Las dos respuestas posibles son:

(1) C3 es una ley promulgada; pero al no ser promulgada por otra autoridad con poder de hacerlo, solo se puede concluir que se promulgó por A3;

(2) C3 no es una ley promulgada; esto significa que su validez legal no puede ser derivada de la validez de otra norma, por lo que su validez solo puede darse por supuesta.

(iii) Las paradojas pueden ser resueltas y explicadas de una manera muy elemental sin necesidad de una teoría compleja como aquella de los tipos lógicos de Russell.

(iv) Una formulación sencilla de una teoría así es necesaria con el fin de explicar los usos sintácticos de la palabra "todos".

La cuestión central para Jörgensen es que las oraciones que se denominan autorreferentes no son oraciones en un sentido lógico pues carecen de lo que en lógica y la filosofía del lenguaje se denomina, "referencia". JÖRGENSEN (1953), p. 289.

16 Alf Ross defendió la tesis de la imposibilidad racional -tanto lógica como jurídica- de reformar la norma que establece el procedimiento de reforma por medio de ese mismo procedimiento. Ross presentó esta posición por primera vez en su obra Sobre el Derecho y la Justicia y la desarrolló más ampliamente en un artículo posterior publicado en la revista Mind. El puzle que plantea Ross se basa en la pregunta de si la norma sobre reforma constitucional puede ser considerada como parte o perteneciente a la Constitución y, al mismo tiempo, como una norma que se encuentra sujeta al mecanismo de reforma o enmienda que ella misma establece. Ross, Alf (1969), pp. 1-24. 
La segunda tesis en contra de la validez es propuesta por el profesor español José Juan Moreso, quien sostiene: “[...] una disposición de reforma constitucional [RC] no puede ser reformada válidamente por el procedimiento por ella misma establecido, porque ello supone delegar la competencia de reforma constitucional, vulnerando así la reserva de constitución establecida por [RC]"17. Lo anterior, a juicio de Moreso, si bien implica la invalidez de la norma reformada, no afecta su eficacia, iniciando una nueva cadena de validez, siendo este un supuesto de ruptura constitucional ${ }^{18}$.

En un sentido contrario, las posturas que propician la validez de la modificación de las normas sobre reforma constitucional por el procedimiento establecido por ellas mismas se fundan en lo siguiente: a) Es posible, lógica y jurídicamente, que una norma contemple su propia enmienda. El efecto de esta norma es prescribir que para tal modificación deba utilizarse un mecanismo específico, pero solo hasta que otra norma, promulgada por el mecanismo contemplado, establezca otro procedimiento, y b) Es erróneo afirmar que la reforma de la norma de reforma constitucional, mediante el procedimiento por ella establecido, dé como resultado una norma inválida. Lo anterior implica desconocer el tipo de relación que se da entre la norma de competencia y la norma resultante de la aplicación del procedimiento establecido en la primera. Pues la relación no es solamente de implicancia lógica sino que supone una relación temporal que condiciona la validez de la norma resultante.

La primera idea es planteada por Hart, quien critica la tesis de Ross. Según Hart, Ross afirma que si el artículo 88 de la Constitución danesa es modificado de conformidad con sus propias reglas, no sería posible desprender o derivar la validez del nuevo artículo 88' del artículo 88 reformado (siguiendo la cadena de validez). Cualquier derivación, diría Ross según lo señala Hart, presupone la validez de la norma superior y, por lo tanto, presupone la existencia de la misma. Pero el supuesto de toda derivación de validez desde la perspectiva jurídica es que el producto de la derivación no puede estar en contradicción de la fuente de derivación, justamente porque lo que hace la derivación de validez es un traspaso

\footnotetext{
17 Moreso, José Juan (1991), p. 207.

18 Moreso explica: "Si, a pesar de ello, esta reforma se realiza yo diría que se trata de una reforma inválida y que, por tanto, ha habido lo que se denomina una 'ruptura constitucional', de análoga forma a la que se produce cuando un órgano distinto del órgano competente según $[\mathrm{RC}]$ modifica o sustituye la Constitución (como sucede en las revoluciones políticas). Obviamente una norma inválida (en el sentido de que existe otra norma en el ordenamiento que le atribuye el carácter de no válida) puede ser promulgada y, también, aplicada por los tribunales o ser usada para iniciar una nueva cadena de validez". Moreso (1991), p. 207.
} 
de validez. Solo son válidas las normas que se derivan de otras normas que son, a su vez, válidas. Según Hart, la conclusión a la que llega Ross supone afirmar que por derivación no se puede establecer una nueva norma que entra en conflicto con la fuente de la derivación, por lo que habría un imposible normativo.

Para Hart, dos puntos del argumento que presenta Ross le parecen cuestionables: a) La primera: es la afirmación de que la derivación de una nueva norma presupone no solo la validez de la norma superior, sino su existencia después de la creación de la nueva norma; b) La segunda: es la sugerencia de que si el artículo 88 de la Constitución danesa se modificara de conformidad con sus propias normas, la nueva norma estaría en contradicción con lo presupuesto en la norma de reforma.

Para Hart, una vez que termina la validez de una norma, en los términos contemplados en esa misma norma, deja de existir contradicción pues el resultado del mecanismo autoimpuesto es el término de validez de la anterior y la validez de la nueva. Seguramente, señala Hart, podríamos concebir esto, sin equivocarnos, como un cambio jurídicamente válido sin que importe una contradicción derivada ${ }^{19}$.

Para Joseph Raz, siguiendo muy de cerca el argumento de Hart sobre la relación temporal entre los hechos, el punto central es demostrar que es posible, sin riesgo de incurrir en contradicción lógica alguna o en una inferencia de validez errónea, reformar una norma de reforma constitucional por medio del mecanismo por ella reconocido. Y el argumento de Raz utiliza precisamente el ejemplo de Ross sobre el artículo 88 de la Constitución Danesa de 1953.

Efectivamente, señala Raz, es posible concebir una inferencia inválida para la enmienda o reforma de la norma de reforma constitucional (el artículo 88 en este caso) por medio del mecanismo por ella reconocido ${ }^{20}$.

Para un momento dado T, el artículo 88 es válido. Como señala Raz, esto significa que, en un momento dado (T), la Constitución solo puede ser reformada por medio del mecanismo o procedimiento especial (C) reconocido por el artículo 88. En T, se promulga un nuevo artículo $88^{\prime}$ que establece que la Constitución

19 Hart, en sus Essays in Jurisprudence and Philosophy, critica la tesis de Ross y afirma que tal vez Ross descuida una consideración que es fundamental en este ámbito: la dimensión temporal del artículo de reforma de la Constitución (o, si se prefiere, de la cadena de validez entre el artículo 88 y el artículo 88'). Según Hart, no hay conflicto si el artículo 88 se modifica de conformidad con sus propias disposiciones, pues el artículo 88 original y el artículo modificado se relacionan en diferentes períodos de tiempo: el procedimiento original ha de ser utilizado hasta que sea sustituido por el nuevo, y el nuevo procedimiento se va a utilizar a partir de entonces. HART, H.L.A. (1964), pp. 176 y ss.

20 RAz, Joseph (1972), p. 420. 
solo puede ser reformada por medio del mecanismo o procedimiento especial (C1), de conformidad al procedimiento especial reconocido en el artículo 88.

En un momento posterior (T1), el artículo 88' es válido de la misma manera que lo era el artículo 88 en T. Esto significa que, en T1, decir que el artículo 88' es válido, importa decir que ahora, la Constitución solo puede ser reformada por medio del procedimiento especial (C1) contenido en el artículo 88'.

La cuestión central en este punto es mostrar que la conclusión no es contradictoria con las premisas de la inferencia en la medida que la reforma de la norma de reforma por medio del procedimiento por ella reconocido puede dar como resultado una norma perfectamente válida ${ }^{21}$.

Por su parte, Norbert Höester también presentó una respuesta especialmente categórica. El argumento de Höester contra la formulación de Ross puede resumirse, muy sintéticamente, como sigue: es correcto sostener, tal y como lo hace Ross, que el conjunto de todas las reglas constitucionales que constituyen la potestad constituyente de la máxima autoridad que reconoce un sistema jurídico constitucional particular (C3, según vimos en el ejemplo que expusimos arriba), no podría haber sido promulgada por la máxima autoridad (A3) que tiene la

21 Para Joseph Raz, si la tesis de Ross es válida -esto es, que la autorreferencia referida a las normas de reforma constitucional supone una imposibilidad lógica y jurídica-, surgen de inmediato dos preguntas respecto de las cuales hay que hacerles frente en términos satisfactorios ya que, en caso contrario, el argumento de Ross sería equivocado. Estas cuestiones son: (i) $S$ por un lado, y $S_{1}$ y $S_{2}$ en el otro lado, deben poder describir, ambas, la misma situación jurídica, que, en nuestro caso es atribuir los mismos poderes o potestades normativas a los mismos órganos o sujetos (ser normas de competencia en el sentido de $\mathrm{C}_{\mathrm{n}}$ ). (ii) Si describen la misma situación jurídica, entonces tiene que ser posible demostrar que esta situación implica dos leyes, $1_{1}$ y $1_{2}$, cada una descrita de manera plena por $S_{1}$ y $S_{2}$, respectivamente, y ambas descripciones juntas en $S$. El punto relevante que trata de mostrar Raz es que el argumento de Ross debe ser capaz de demostrar, de manera consistente que cada descripción, que pertenecen a una descripción superior, son ellas mismas normas independientes (tanto $1_{1}$ como $1_{2}$ son independientes de 1 ). Como señala Raz, los problemas de esta naturaleza pueden surgir en cada ámbito del Derecho. En consecuencia, propone considerar el siguiente ejemplo trivial: (1) El robo está prohibido. (2) Los hombres tienen prohibido robar; (3) Las mujeres tienen prohibido robar. Para Raz, es evidente que (2) y (3) efectivamente describen la misma situación jurídica que aquella contenida en (1), pero esto, y este es el punto central de Raz, no significa en sí mismo o no implica que, respecto de (1) hay dos leyes o normas (derivadas válidamente) en el lugar de estas descripciones [(2) y (3)]. El punto que se está criticando es que el argumento de Ross asume, como se indicara más arriba, que las descripciones normativas sobre los mismos supuestos normativos, se desprenden válidamente de la autorreferencia de una norma como (1) y que, en consecuencia, es válido asumir que hay dos leyes o normas para el tipo de supuesto normativo contenido en las descripciones de (2) y (3). Pero como lo demuestra con el ejemplo, el derecho está repleto de ejemplos donde esa condición (independencia de las normas derivadas de un mismo supuesto de hecho) no se cumple, pues no hay duda que del hecho que las mujeres tengan prohibido fumar y que los hombres tengan prohibido fumar en un determinado ordenamiento jurídico, no implica (es más, no es recomendable) afirmar que son dos normas independientes entre sí. RAZ (1972), pp. 415-421. 
potestad constituida por ese conjunto de reglas C3 que reconoce ese sistema constitucional ${ }^{22}$.

Pero la razón de Ross para afirmar lo anterior es, desde la perspectiva de Höester, errónea y no logra distinguir la verdadera razón detrás de esa imposibilidad que, bien entendida, en nada importa una invalidación a una reforma de la norma de reforma por medio del mecanismo por ella establecido.

Para Höester, dado que la máxima autoridad reconocida por el sistema constitucional (A3) está constituido por el conjunto de todas las reglas que, al mismo tiempo, constituyen la potestad de esa autoridad (C3), entonces, necesariamente la máxima autoridad (A3) presupone, para su validez, la existencia del conjunto de todas las reglas que constituyen la potestad de la máxima autoridad (C3).

Además, señala Höester, no tiene sentido alguno afirmar de la máxima autoridad constitucionalmente reconocida, por definición una autoridad constituida, puede promulgar el conjunto de reglas que habrá de reconocerle ese carácter, esto es, que se constituye a sí misma como una autoridad (A3 se constituye en autoridad al promulgar el conjunto de normas que determinan la potestad para ser considerada autoridad suprema).

Höester señala que nadie puede hacerse o transformarse en algo que ya es. Que A3 no puede promulgar C3, contrariamente a lo que afirma Ross, no tiene nada que ver con algún teorema lógico general que prohíba la autorreferencia ${ }^{23}$.

\section{B. El silencio de la dogmática constitucional chilena}

Escasa atención ha recibido el asunto -validez o invalidez de las normas que modifican las normas sobre la reforma constitucional- en nuestro medio constitucional. Los autores nacionales han asumido al respecto las siguientes posiciones: a) detectan el debate y lo descartan; b) detectan el debate y lo resuelven en favor de la validez de las normas que modifican las normas sobre la reforma constitucional al considerar que no hay límites materiales al poder reformador y que la propia Constitución prevé tal reforma asignándole un quórum reforzado para su aprobación, en cada Cámara, de las dos terceras partes de los diputados y senadores en ejercicio, de conformidad con el artículo 127 constitucional; c) omiten el debate a pesar de que estiman que existen límites materiales explícitos e incluso implícitos al poder constituyente derivado.

22 HÖEster, Norbert (1972), pp. 422-426.

23 HÖEster (1972), p. 423. 
En el contexto de la primera postura, Francisco Zúñiga atiende el asunto para descartar de plano el problema de la autorreferencia normativa: "La operación constituyente propuesta hace más de un lustro en otros trabajos de nuestra autoría está abierta a dos caminos: al poder constituyente derivado o poder de reforma total permitida por el capítulo XV y en las coordenadas de la Constitución vigente, saltando por los aires el problema de la autorreferencia (Ross) o al poder constituyente originario, como único recurso para salvar el bloqueo constitucional impuesto en la Constitución desde una lógica autoritaria contramayoritaria" ${ }^{24}$.

En el marco de la segunda postura, en un trabajo previo, se expuso la tesis que no existen límites materiales al poder reformador y que es válido modificar el capítulo XV de la Constitución, citando expresamente la discusión iniciada por Ross y proseguida por Moreso. En sus términos: "De la lectura del propio articulado del Capítulo XV, es posible colegir que la Constitución permite incluso la modificación, sin reserva o excepción alguna, de aquellos capítulos -en los que la posición contraria ha reconocido se encontrarían los límites implícitos- que versan sobre las bases de la institucionalidad (I) y los derechos y deberes constitucionales (III), incluso admitiendo la reforma del propio capítulo dedicado a la reforma (XV), exigiendo para ello solo un quórum más agravado que para el resto de las materias: esto es, 2/3 de los diputados y senadores en ejercicio" 25 .

En el último supuesto se encuentran los autores que han dedicado trabajos especializados a los límites materiales, explícitos e implícitos, sin referir como tales las normas sobre la producción de la reforma constitucional26.

\section{A MODO DE CONCLUSIÓN: UN INSUMO PARA EL DEBATE CONSTITUCIONAL}

El dictado de una nueva Constitución o la reforma total de la vigente, originados en una reforma previa de las normas sobre reforma constitucional

24 ZÚNIGA (2013), p. 531.

25 Henríquez (2011), p. 465.

26 A modo de ejemplo, Humberto Nogueira sostiene la existencia de límites procedimentales y materiales, explícitos e implícitos, sin contar entre ellos los relativos a las normas sobre reforma constitucional: "La Constitución chilena únicamente prevé y establece los procedimientos para la operación de un poder constituyente derivado o poder de reforma de la Constitución, el cual no puede alterar la identidad y continuidad de la Constitución ni la fórmula política de ella, como asimismo, forman parte de este límite material los atributos de los derechos fundamentales asegurados por el texto constitucional y por el derecho internacional vinculante y vigente, ya que éste constituye un límite al ejercicio de la soberanía como establece con absoluta claridad el artículo $5^{\circ}$ inciso segundo de la Constitución". Nogueira, Humberto (2009), p. 262. 
a través de los mecanismos previstos por ellas, parece un escenario, aunque difícil, posible.

En tal contexto estimamos que contribuye al debate constitucional en ciernes cuestionarse si la modificación de las normas sobre la reforma, contenidas actualmente en el capítulo XV, es una vía o alternativa que será considerada válida en un eventual control previo de constitucionalidad por el Tribunal Constitucional.

Escasa atención ha recibido en nuestro medio constitucional el debate sobre la validez de las normas que modifican las normas sobre la reforma constitucional. Su consideración parece necesaria, puesto que ella implica la discusión sobre los modos de creación del Derecho chileno, la naturaleza de las normas sobre la reforma y las normas de reforma constitucional, el concepto mismo de reforma constitucional, de cambio constitucional y de la propia validez del Derecho. Este último trae a su vez aparejado los temas relativos al fundamento de la obligatoriedad del Derecho, de la unidad de los sistemas jurídicos, de la noción de cambio y la dinámica jurídica.

Seguimos en gran medida los argumentos de los detractores de la tesis de Ross: son válidas las modificaciones de las normas sobre la reforma constitucional conforme al procedimiento que establecen estas últimas. Particularmente atendibles parecen las razones expuestas por Hart en orden que no hay conflicto si una norma sobre la reforma se modifica de conformidad con sus propias disposiciones, pues la norma sobre la reforma original y la norma sobre la reforma modificada se relacionan en diferentes períodos de tiempo: el procedimiento original ha de ser utilizado hasta que sea sustituido por el nuevo, y el nuevo procedimiento se usará a partir de entonces.

Pero si acaso hay una razón que trasciende tanto la realidad chilena como los presupuestos abstractos, esa lo constituye la relación entre la Constitución de un pueblo y el reconocimiento del pueblo en esa Constitución. En el sentido de Elster, el precompromiso de una Constitución supone un reconocimiento válido de restricción para generar una obligación futura de respeto.

Los mecanismos de reforma de las constituciones modernas suponen asumir institucionalmente la restricción futura de la voluntad que se dio una Constitución. Esa restricción futura es la determinación del procedimiento y los sujetos legitimados para reformar una Constitución. Desde la perspectiva de la teoría del derecho, dicha autorrestricción es, además, uno de los supuestos de validez del sistema. El correlato institucional de esta autorrestricción en el caso chileno, es el capítulo XV de la Constitución.

Además, y a modo de conclusión final, corresponde señalar: a) La Constitución chilena admite explícitamente la modificación del capítulo XV con el requisito de lograr el altísimo quórum de las dos terceras partes de los senadores 
y diputados en ejercicio; b) La Constitución chilena no prohíbe su reforma total, por tanto tampoco prohíbe lo menos, es decir, la modificación de las normas sobre la reforma constitucional, y c) Las normas sobre la reforma constitucional, tal como se encuentran estructuradas, son normas de competencia que también permiten delegar la competencia de reformar la Constitución.

\section{BiBLIOGRAFÍA}

ACKerman, Bruce (1989): "Constitutional Politics/Constitutional Law", en The Yale Law Journal, Vol. 99, 3, pp. 453-547.

Alchourrón, Carlos y Bulygin, Eugenio (1974): Introducción a la metodología de las ciencias jurídicas y sociales (Buenos Aires, Astrea).

AtriA, Fernando (2013): La Constitución tramposa (Santiago, LOM).

BöCKENFORDE, Ernst Wolfgang (2000): Estudios sobre el Estado de Derecho y la Democracia (Madrid, Trotta).

De Cabo Martín, Carlos (2003): La Reforma constitucional en la perspectiva de las Fuentes del Derecho (Madrid, Trotta).

FINNIS, John (1973): "Revolutions and Continuity of Law", en Oxford Essays of Jurisprudence, 59, A.W. Simpson ed.

GinsBurg, Tom (2014): “¿Fruto de la parra envenenada? Algunas observaciones comparadas sobre la Constitución chilena”, en Estudios Públicos, 133, pp. 1-36.

Hart, H.L.A. (1994): The Concept of Law (Oxford, The Clarendon Press).

Hart, H.L.A. (1964): "Self-Referring Laws", en Essays in Jurisprudence and Philosophy, Oxford, Oxford University Press, pp. 170-179.

Henríquez, Miriam (2011): "El control de constitucionalidad de la reforma constitucional en el ordenamiento constitucional chileno", en Anuario Derecho Público UDP, pp. 461-477.

HÖERSTER, Norbert (1972): "On Alf Ross's alleged puzzle in constitutional law", en Mind, 81, pp. 422-426.

JörGENSEN, Jorgen (1953): "Some reflections on reflexivity", en Mind, 62, pp. 289-300.

Kelsen, Hans (1963): Teoría Pura del Derecho (México, Porrúa).

Moreso, José Juan (1991): “Disposiciones de reforma constitucional”, en Doxa, 10, pp. 201-222.

Nogueira Alcalá, Humberto (2009): “Consideraciones sobre poder constituyente y reforma de la Constitución en la teoría y la práctica constitucional”, en Revista Ius et Praxis, Vol 15, No 1, pp. 229-262. 
Popper, Karl R. (1967): Conjeturas y Refutaciones (Barcelona, Paidós).

Raz, Joseph (1972): "Professor Alf Ross and some legal puzzles", en Mind, 81, pp. 415-421.

Ríos, Lautaro (2013): “¿Es necesaria una Nueva Constitución?”, en Revista de Derecho Público, Vol. 78, pp. 205-222.

Ross, Alf (1969): "On Self-Reference and a puzzle in constitutional law", en Mind, 78, pp. 1-24.

Ruiz Tagle, Pablo (2012): "Desobediencia civil, terrorismo y derechos fundamentales", en Revista Derecho y Humanidades, No 12, pp. 133-140.

ZúNiga, Francisco (2013): "Nueva Constitución y operación constituyente. Algunas notas acerca de la Reforma Constitucional y de la Asamblea Constituyente", en Revista Estudios Constitucionales, Año 11, No 1, pp. 511-540.

ZúŇIgA, Francisco (2014): "Nueva Constitución para Chile. Las 'bases' y las nuevas ideas político-constitucionales, en Revista de Derecho Público, edición especial, pp. 25-40.

ZúŃIGA, Francisco (2014): "Potestad constituyente”, en Revista de Derecho. Escuela de Postgrado, No 5, pp. 307-318. 